\title{
Synthesis of Imidazo [1, 2-a] Pyridine Derivatives Using Copper Silicate as an Efficient and Reusable Catalyst
}

\author{
Ajit Dhas 1, Satish Deshmukh ${ }^{1}$, Dattatraya Pansare ${ }^{1}$, Rajendra Pawar 1, *, Gopal Kakade ${ }^{\text {,** }}$ \\ Department of Chemistry, Deogiri College, Aurangabad 431005, Maharashtra, India \\ Art's, Commerce and Science College, Kille-Dharur, Beed 431124, Maharashtra, India \\ Correspondence: rppawar@yahoo.com (R.P.); gk_kakade@rediffmail.com (G.K.);
}

Scopus Author ID 7003738785

Received: 20.12.2020; Revised: 12.01.2021; Accepted: 15.01.2021; Published: 20.01.2021

\begin{abstract}
Synthesis of imidazo [1, 2-a] pyridines derivatives were reported from 2-aminopyridine and various substituted phenacyl bromide using copper silicate as an efficient, eco-friendly, and reusable catalyst. The present protocol offers various advantages, such as the use of less hazardous solvent, high yield, and operationally simple procedure.
\end{abstract}

Keywords: copper silicate; imidazo [1, 2-a] pyridines; 2-amino pyridine; phenacyl bromides.

(C) 2020 by the authors. This article is an open-access article distributed under the terms and conditions of the Creative Commons Attribution (CC BY) license (https://creativecommons.org/licenses/by/4.0/).

\section{Introduction}

Fused heterocyclic compounds containing nitrogen have received considerable attention due to their wide biological activities [1]. Imidazo [1, 2-a] pyridine scaffolds are more attractive due to their applications in pharmaceuticals such as antiviral [2-4], antibacterial [5], antifungal [6], anticancer [7,8], and anti-inflammatory [9] agents. Imidazo [1, 2-a] pyridine as a core structure represents leading drugs in the market such as zolpidem (I), alpidem (II), olprinone (III), minodronic acid (IV), zolimidine (V), saripidem (VI), and miroprofen (VII) (Fig. 1) [10-11]. Several reports on the synthesis of imidazolo [1, 2-a] pyridine proceed through the condensation reaction of various substituted $\alpha$-bromo carbonyl compounds with 2 -amino pyridine the presence of a variety of catalyst. The importance of the Imidazo [1, 2-a] pyridine scaffold as biologically active compounds and ligands for metal catalysts makes it an attractive moiety for the development of a new synthetic method for their preparation [10 - 11]. Cyclization of 2-aminopyridines with phenacyl bromide is the classical method for the synthesis of substituted imidazo [1,2-a]pyridine. The method utilizes various catalyst which includes iodine[12], hypervalent iodine[13], $\mathrm{SnCl}_{2}$ [14], $\mathrm{MgO}$ [15], gold[16], copper NPs[17], Pd(II)[18], DBU[19], DABCO[20]. Non-conventional heating methods, which include microwave[21], grinding[22], and ultrasound[23], are also successfully reported. However, these reported methodologies suffer from some drawbacks like high temperatures, long reaction times, and toxic metal catalysts, expensive, harmful reagents, and solvents. Despite these efforts, it is still a challenge to synthesize the functionalized Imidazo [1, 2-a] pyridines from the readily available starting materials.

In continuation of our previous work here, we employed copper silicate as a heterogeneous catalyst to develop a rapid and efficient process for the synthesis of imidazo [1, 2-a] pyridines [24]. 


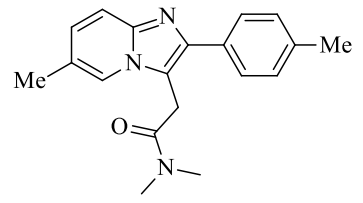

Zolpidem (sedative)

(I)

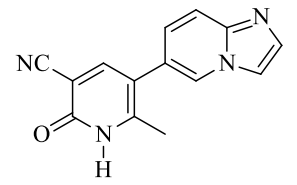

Olprinone (PDE-III inhibitor)

(IV)

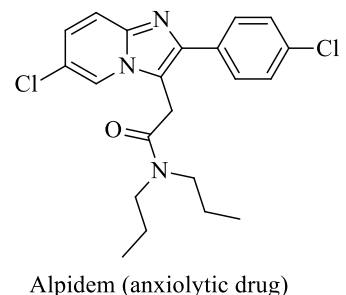

(II)

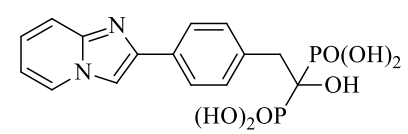

Minodronic acid (to treat osteoporosis)

(V)

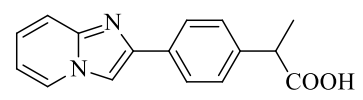

Miroprofen (analgesic)

(VII)

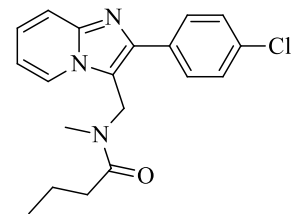

Saripidem (anxiolytic drug)

(III)

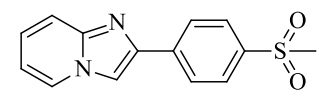

Zolimidine (to treat peptic ulcer) (VI)

Figure 1. Representative drug molecules containing imidazo [1, 2-a] pyridine moiety.

\section{Materials and Methods}

\subsection{General.}

All Chemicals were purchased from SD Fine and spectrochem used without further purification. Melting points of the products were recorded in open capillaries in a liquid paraffin bath and are uncorrected. The reaction was monitored by thin-layer chromatography (TLC) in $20 \%$ (ethyl acetate: n-hexane) on silica gel precoated aluminum foil (Merck). IR spectra were recorded in $\mathrm{KBr}$ disc on Shimadzu-FT-IR Spectrophotometer, and absorption bands are expressed in $\mathrm{cm}^{-1}$. $1 \mathrm{H}$ spectra were recorded on a Bruker Avance Neo $500 \mathrm{NMR}$ Spectrometer instrument in DMSO-d6 as solvent and TMS as the internal standard. Mass spectra were recorded on Waters Q-TOF micromass spectrophotometer.

\subsection{General procedure for the synthesis of Imidazo [1, 2-a] pyridines derivatives.}

In a round bottom flask, 2 -amino pyridine ( 1 mmole), substituted phenacyl bromide (1 mmole) (2a-k), and copper silicate catalyst (10 mole \%) was added to $5 \mathrm{ml}$ ethanol. The reaction mixture was refluxed, and the progress of the reaction was monitored by thin-layer chromatography using hexane: ethyl acetate $(8: 2)$ as a mobile phase. After completing the reaction, the reaction mixture was filtered to isolate the catalyst and then poured over crushed ice to obtain a solid product. The isolated crude product was purified by recrystallization using hot ethanol. Other analogs of this series were prepared, and tabulated data of various derivatives is mention in Table 4. Their structures have been confirmed by analytical methods such as mp, ${ }^{1} \mathrm{H}$ NMR, Mass Spectra, and IR spectra.

\subsection{Spectral data.}

Synthesis of 2-(4-methoxyphenyl)imidazo[1,2-a]pyridine (3c), Yield 89\%; MP 132$134{ }^{0} \mathrm{C}$; $1 \mathrm{H}$ NMR (500 MHz, DMSO-d6) $\delta 8.9(\mathrm{~d}, 1 \mathrm{H}), 8.7(\mathrm{~s}, 1 \mathrm{H}), 7.95(\mathrm{~d}, 2 \mathrm{H}), 7.90(\mathrm{~d}, 2 \mathrm{H})$, 
7.52-7.49 (m, 1H), $7.18(\mathrm{~d}, 2 \mathrm{H}), 3.85(\mathrm{~s}, 3 \mathrm{H})$; IR(KBr, cm $\left.{ }^{-1}\right): 3363(\mathrm{C}-\mathrm{H}), 3132(\mathrm{Ar}-\mathrm{H})$, 1665 $(\mathrm{C}=\mathrm{N}), 1550(\mathrm{C}=\mathrm{C}), 1257(\mathrm{C}-\mathrm{O}), 760(\mathrm{C}-\mathrm{H}$ bend $) ;[\mathrm{M}+1]+-225.51$

Synthesis of 2-(4-nitrophenyl)imidazo[1,2-a]pyridine (3b), Yield 95\%; MP 203-207 ${ }^{0} \mathrm{C}$;1H NMR (500 MHz, DMSO-d6) $\delta 8.65(\mathrm{~s}, 1 \mathrm{H}), 8.58(\mathrm{~d}, 1 \mathrm{H}), 8.31(\mathrm{~d}, 2 \mathrm{H}), 8.23(\mathrm{~d}, 2 \mathrm{H})$, $7.63(\mathrm{~d}, 1 \mathrm{H}), 7.30-7.27(\mathrm{~m}, 1 \mathrm{H}), 6.96(\mathrm{~m}, 1 \mathrm{H})$; IR(KBr, $\left.\mathrm{cm}^{-1}\right): 3350(\mathrm{C}-\mathrm{H}), 3140(\mathrm{Ar}-\mathrm{H})$, $1670(\mathrm{C}=\mathrm{N}), 1500(\mathrm{~N}-\mathrm{O}$ stretch$), 1220(\mathrm{C}-\mathrm{N}), 740(\mathrm{C}-\mathrm{H}$ bend $) ;[\mathrm{M}+1]+-240.07$

\section{Results and Discussion}

The reaction of 2-amino pyridine (1) and phenacyl bromide (2a) is considered as a model reaction (Figure 2) for the development of methodology. The model reaction was investigated with various catalysts few of them are mentioned in Table 1. The lesser yield was observed when the reaction was carried out without catalyst (Table 1, entry 1). Low yields were found when the reaction was catalyzed by a basic catalyst such as $\mathrm{DBU}$ and $\mathrm{NaHCO}_{3}$ (Table 1, entries 2, 3). Marginal improvement in the yield of the product was observed in the presence of Lewis acid catalysts such as $\mathrm{ZnO}, \mathrm{FeCl}_{3}$, and $\mathrm{AlCl}_{3}$ (Table 1, entries 4, 5, and 6). We observed the best results when the reaction was catalyzed by copper silicate (Table 1, entry 7). This finding shows that the reaction was effectively catalyzed by copper silicate.

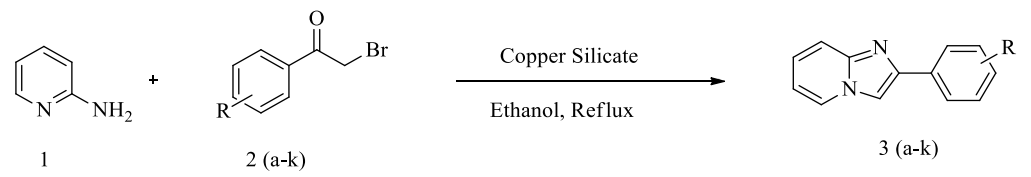

Figure 2. Synthesis of substituted imidazo [1, 2-1].

In order to study the screening of solvent, the model reaction was carried out in various solvents. Moderate yields were observed when the reaction was carried out in less polar solvents such as dichloromethane and toluene (Table 2, entries 1 and 2). At the same time, significant improvement in the yield of the product was observed in polar solvents such as methanol and acetonitrile (Table 2, entries 3 and 4). The lesser yield was reported in the presence of water (Table 2, entry 6). The best results were obtained in ethanol as a solvent at reflux condition, making it the most suitable solvent for the reaction (Table 2, entry 5).

Subsequently, we investigated the optimal concentration of catalyst in the model reaction; lowering the amount of catalyst to 5 mole $\%$ lowers the desired product's yield to $69 \%$ (Table 3, entry 1). However, optimal results were obtained with 10 mole $\%$ catalyst loading (Table 3, entry 2).

Based on the optimized reaction conditions, we performed the reactions of various substituted phenacyl bromide 2(a-k) to expand the method's applications. The results are summarized in Table 4.

In order to make the process useful for large scale preparation, we examined the recycling of the catalyst. After completing the reaction, the catalyst was recollected using an external magnet from the reaction mixture, washed, dried, and reused for the next cycle. The recycling data are summarized in Table 5, indicating a slight decrease in the yield of the product up to the third cycle, then after the yield decreases considerably.

Table 1. Screening of various catalysts for the synthesis of Imidazo [1, 2-a] pyridines derivatives.

\begin{tabular}{l|c|c|c|c|c} 
Entry & Catalysts & Solvent & Temperature $\left({ }^{\mathbf{0}} \mathbf{C}\right)$ & Time (h) & Yield (\%) \\
\hline 1 & -- & Ethanol & Reflux & 8 & 45 \\
\hline 2 & $\mathrm{DBU}$ & Ethanol & Reflux & 4 & 60 \\
\hline 3 & $\mathrm{NaHCO}_{3}$ & Ethanol & Reflux & 6 & 65 \\
https://nanobioletters.com/ & & & & $\mathbf{2 5 6 7}$
\end{tabular}




\begin{tabular}{l|c|c|c|c|c}
\hline Entry & Catalysts & Solvent & Temperature ( $\mathbf{(}^{\mathbf{C})}$ & Time (h) & Yield (\%) \\
\hline 4 & $\mathrm{ZnO}$ & Ethanol & Reflux & 4 & 72 \\
\hline 5 & $\mathrm{FeCl}_{3}$ & Ethanol & Reflux & 4 & 75 \\
\hline 6 & $\mathrm{AlCl}_{3}$ & Ethanol & Reflux & 3 & 69 \\
\hline 7 & Copper silicate & Ethanol & Reflux & 1.5 & 94
\end{tabular}

Table 2. Screening of various solvents for the synthesis of Imidazo [1, 2-a] pyridines derivatives at reflux temperature.

\begin{tabular}{c|c|c|c|c} 
Entry & Solvent & Catalyst $(\boldsymbol{\%})$ & Time (h) & Yield (\%) \\
\hline 1 & Dichloro methane & 10 & 7 & 58 \\
\hline 2 & Toluene & 10 & 7 & 58 \\
\hline 3 & Methanol & 10 & 5 & 72 \\
\hline 4 & Acetonitrile & 10 & 5 & 84 \\
\hline 5 & Ethanol & 10 & 1.5 & 94 \\
\hline 6 & Water & 10 & 5 & 30
\end{tabular}

Table 3. Effect of concentration of catalyst for the synthesis of Imidazo [1, 2-a] pyridines derivatives.

\begin{tabular}{c|c|c|c|c|c} 
Entry & $\begin{array}{c}\text { Catalyst } \\
(\text { Mole \%) }\end{array}$ & Solvent & $\begin{array}{c}\text { Time } \\
(\mathbf{h})\end{array}$ & $\begin{array}{c}\text { Temperature } \\
\left({ }^{\mathbf{0}} \mathbf{C}\right)\end{array}$ & $\begin{array}{c}\text { Yield } \\
(\mathbf{\%})\end{array}$ \\
\hline 1 & 5 & Ethanol & 3.5 & Reflux & 75 \\
\hline 2 & 10 & Ethanol & 1.5 & Reflux & 94 \\
\hline 3 & 15 & Ethanol & 1.5 & Reflux & 94
\end{tabular}

Table 4. Synthesis of Imidazo [1, 2-a] pyridine derivatives.

\begin{tabular}{c|c|c|c|c|c} 
Entry & Compound & Aldehyde (2a-k) & Time $(\mathbf{h})$ & Yield (\%) & M. P. $\left({ }^{\mathbf{0}} \mathbf{C}\right)$ \\
\hline 1 & $3 \mathrm{a}$ & $-\mathrm{H}$ & 1.5 & 94 & $134-137$ \\
\hline 2 & $3 \mathrm{~b}$ & $4-\mathrm{NO}_{2}$ & 1.0 & 95 & $203-207$ \\
\hline 3 & $3 \mathrm{c}$ & $4-\mathrm{OCH}_{3}$ & 2.0 & 89 & $132-134$ \\
\hline 4 & $3 \mathrm{~d}$ & $4-\mathrm{Cl}_{3}$ & 2.0 & 86 & $206-208$ \\
\hline 5 & $3 \mathrm{e}$ & $3-\mathrm{CH}_{3}$ & 2.0 & 88 & $100-103$ \\
\hline 6 & $3 \mathrm{f}$ & $4-\mathrm{F}$ & 1.5 & 83 & $161-164$ \\
\hline 7 & $3 \mathrm{~g}$ & $4-\mathrm{CH}_{3}$ & 2.5 & 90 & $145-147$ \\
\hline 8 & $3 \mathrm{~h}$ & $3-\mathrm{NO}_{2}$ & 2.0 & 87 & $202-205$ \\
\hline 9 & $3 \mathrm{i}$ & $4-\mathrm{Br}$ & 2.5 & 88 & $209-213$ \\
\hline 10 & $3 \mathrm{j}$ & $2-\mathrm{Br}$ & 2.5 & 85 & $84-88$ \\
\hline 11 & $3 \mathrm{k}$ & $2-\mathrm{OH}$ & 2.5 & 85 & $141-145$
\end{tabular}

\section{Conclusions}

Herein we describe an efficient synthesis of imidazo [1, 2-a] pyridine from 2aminopyridines and various substituted phenacyl bromide catalyzed by copper silicate. The work offers several practical advantages: short reaction time, less hazardous solvent, and high yield. Moreover, the present protocol is operationally simple and could be applied for large scale synthesis.

\section{Funding}

This research received no external funding.

\section{Acknowledgments}

This research has no acknowledgment.

\section{Conflicts of Interest}

The authors declare no conflict of interest. 


\section{References}

1. Heravi, M.M.; Daraie, M.; Zadsirjan, V. Current advances in the synthesis and biological potencies of triand tetra-substituted 1H-imidazoles. Molecular Diversity 2015, 19, 577-623, https://doi.org/10.1007/s11030-015-9590-6.

2. Gueiffier, A.; Mavel, S.; Lhassani, M.; Elhakmaoui, A.; Snoeck, R.; Andrei, G.; Chavignon, O.; Teulade, J.C.; Witvrouw, M.; Balzarini, J.; De Clercq, E.; Chapat, J.-P. Synthesis of Imidazo[1,2-a]pyridines as Antiviral Agents. Journal of Medicinal Chemistry 1998, 41, 5108-5112, https://doi.org/10.1021/jm981051y.

3. Lhassani, M.; Chavignon, O.; Chezal, J.-M.; Teulade, J.-C.; Chapat, J.-P.; Snoeck, R.; Andrei, G.; Balzarini, J.; Clercq, E.; Gueiffier, A. ChemInform Abstract: Synthesis and Antiviral Activity of Imidazo[1,2a]pyridines. Cheminform 2010, 30 .

4. Chaouni-Benabdallah, A.; Galtier, C.; Allouchi, H.; Kherbeche, A.; Debouzy, J.-C.; Teulade, J.-C.; Chavignon, O.; Witvrouw, M.; Pannecouque, C.; Balzarini, J.; de Clercq, E.; Enguehard, C.; Gueiffier, A. Synthesis of 3-Nitrosoimidazo[1,2-a]pyridine Derivatives as Potential Antiretroviral Agents. Archiv der Pharmazie 2001, 334, 224-228, https://doi.org/10.1002/1521-4184(200107)334:7<224::AIDARDP224>3.0.CO;2-7.

5. Lv, K.; Li, L.; Wang, B.; Liu, M.; Wang, B.; Shen, W.; Guo, H.; Lu, Y. Design, synthesis and antimycobacterial activity of novel imidazo[1,2-a]pyridine-3-carboxamide derivatives. European Journal of Medicinal Chemistry 2017, 137, 117-125, https://doi.org/10.1016/j.ejmech.2017.05.044.

6. Husain, A.; Drabu, S.; Kumar, N.; Alam, M. M.; Bawa, S. Synthesis and Biological Evaluation of Di- and Tri-Substituted Imidazoles as Safer Anti-Inflammatory-Antifungal Agents. J Pharm Bioallied Sci2013, 5, 154-161, https://doi.org/10.4103/0975-7406.111822.

7. Romagnoli, R.; Baraldi, P.G.; Prencipe, F.; Oliva, P.; Baraldi, S.; Tabrizi, M.A.; Lopez-Cara, L.C.; Ferla, S.; Brancale, A.; Hamel, E.; Ronca, R.; Bortolozzi, R.; Mariotto, E.; Basso, G.; Viola, G. Design and Synthesis of Potent in Vitro and in Vivo Anticancer Agents Based on 1-(3',4',5'-Trimethoxyphenyl)-2-Aryl1H-Imidazole. Scientific Reports 2016, 6, https://doi.org/10.1038/srep26602.

8. Ye, Z.; Liu, C.; Zou, F.; Cai, Y.; Chen, B.; Zou, Y.; Mo, J.; Han, T.; Huang, W.; Qiu, Q.; Qian, H. Discovery of novel potent GPR40 agonists containing imidazo[1,2-a]pyridine core as antidiabetic agents. Bioorganic \& Medicinal Chemistry 2020, 28, https://doi.org/10.1016/j.bmc.2020.115574.

9. Almasirad, A.; Mousavi, Z.; Tajik, M.; Assarzadeh, M.J.; Shafiee, A. Synthesis, analgesic and antiinflammatory activities of new methyl-imidazolyl-1,3,4-oxadiazoles and 1,2,4-triazoles. DARU Journal of Pharmaceutical Sciences 2014, 22, https://doi.org/10.1186/2008-2231-22-22.

10. Aakash, D.; Richa Kaur, B.; Ramanjot, K.; Sanjiv, K.; Upendra Kumar, J.; Harinder, S.; Sandeep, B.; Dinesh, K.; Pran Kishore, D. Imidazo[1,2-a]pyridine Scaffold as Prospective Therapeutic Agents. Current Topics in Medicinal Chemistry 2017, 17, 238-250, https://doi.org/10.2174/1568026616666160530153233.

11. Nisha, D.; Dharmender, S.; Ravindra, K.R.; Jitender, B.; Virender, S. Medicinal Attributes of Imidazo[1,2a]pyridine Derivatives: An Update. Current Topics in Medicinal Chemistry 2016, 16, 2963-2994, https://doi.org/10.2174/1568026616666160506145539.

12. Xing, M.-M.; Xin, M.; Shen, C.; Gao, J.-R.; Jia, J.-H.; Li, Y.-J. Iodine-promoted oxidative coupling reaction: a simple and efficient process to access imidazo[1,2-a]pyridines from 2-aminopyridines and chalcones. Tetrahedron 2016, 72, 4201-4204, https://doi.org/10.1016/j.tet.2016.05.052.

13. Huang, H.-Y.; Hou, R.-S.; Wang, H.-M.; Chen, L.-C. Hypervalent Iodine(III) Sulfonate Mediated Synthesis of Imidazo[1,2-a]pyridines. Journal of the Chinese Chemical Society 2004, 51, 1377-1380, https://doi.org/10.1002/jccs.200400201.

14. Shaabani, A.; Soleimani, E.; Sarvary, A.; Rezayan, A.H.; Maleki, A. ChemInform Abstract: Tin(II) Chloride Dihydrate Catalyzed Groebke Condensation: An Efficient Protocol for the Synthesis of 3Aminoimidazo[1,2-a]pyridines. ChemInform 2009, 40, https://doi.org/10.1002/chin.200927145.

15. Patil, S.V.; Gaikwad, N.D.; Bobade, V.D. A simple and efficient synthesis of imidazolo[1,2-a]pyridines using $\mathrm{MgO}$ in aqueous medium. Arabian Journal of Chemistry 2016, 9, S1649-S1653, https://doi.org/10.1016/j.arabjc.2012.04.017.

16. Talbot, E.P.A.; Richardson, M.; McKenna, J.M.; Toste, F.D. Gold-Catalyzed Redox Synthesis of Imidazo[1,2-a]pyridines using Pyridine N-Oxide and Alkynes. Advanced Synthesis \& Catalysis 2014, 356, 687-691, https://doi.org/10.1002/adsc.201300996.

17. Sun, W.; Jiang, W.; Zhu, G.; Li, Y. Magnetic Cu0@HAP@ $\gamma-F e 2 O 3$ nanoparticles: An efficient catalyst for one-pot three-component reaction for the synthesis of imidazo[1,2-a]pyridines. Journal of Organometallic Chemistry 2018, 873, 91-100, https://doi.org/10.1016/j.jorganchem.2018.07.039.

18. Wang, Y.; Frett, B.; Li, H.-Y. Efficient Access to 2,3-Diarylimidazo[1,2-a]pyridines via a One-Pot, LigandFree, Palladium-Catalyzed Three-Component Reaction under Microwave Irradiation. Organic Letters 2014, 16, 3016-3019, https://doi.org/10.1021/ol501136e.

19. Veer, B.; Singh, R. Facile synthesis of 2-arylimidazo[1,2-a]pyridines catalysed by DBU in aqueous ethanol. Proceedings of the Royal Society A: Mathematical, Physical and Engineering Sciences 2019, 475, https://doi.org/10.1098/rspa.2019.0238. 
20. Murthy, S.N.; Madhav, B.; Nageswar, Y.V.D. DABCO as a mild and efficient catalytic system for the synthesis of highly substituted imidazoles via multi-component condensation strategy. Tetrahedron Letters 2010, 51, 5252-5257, https://doi.org/10.1016/j.tetlet.2010.07.128.

21. Mert-Balci, F.; Conrad, J.; Beifuss, U. Microwave-assisted three-component reaction in conventional solvents and ionic liquids for the synthesis of amino-substituted imidazo[1,2-a]pyridines. ARKIVOC: archive for organic chemistry 2012, 2012, https://doi.org/10.3998/ark.5550190.0013.318.

22. Zhu, D.; Chen, J.; Wu, D.; Liu, M.; Ding, J.; Wu, H. An Efficient, Catalyst- and Solvent-Free Synthesis of imidazo[1,2-a]pyridines and 2,4-disubstituted thiazoles on Grinding. Journal of Chemical Research 2009, 2009, 84-86, https://doi.org/10.3184/030823409X401844.

23. Vieira, B.M.; Padilha, N.; Nascimento, N.M.; Perin, G.; Alves, D.; Schumacher, R.F.; Lenardão, E.J. Ultrasound-Assisted Synthesis of Imidazo[1,2-a]Pyridines and Sequential One-Pot Preparation of 3-SelanylImidazo[1,2-a]Pyridine Derivatives. Arkivoc 2019, 2019, 6-23, https://doi.org/10.24820/ark.5550190.p010.972.

24. Ajit, K. Dhas.; Satish, U. Deshmukh.; Amol, J. Shirsat; Rajendra, P. Pawar.; Gopal, K. Kakade. Copper Silicate Catalyzed Efficient Synthesis of 2, 4, 5-Trisubstituted imidazole Derivatives via Multicomponent approach. Curr. Pharm. Res.2019, 413, 104-109, https://doi.org/10.33786/JCPR.s2019.413. 